\title{
RUWA JURAI
} JURNAL KESEHATAN LINGKUNGAN

\section{PUBLISH BY :}

JURUSAN KESEHATAN LINGKUNGAN POLITEKNIK KESEHATAN TANJUNGKARANG

ruwajurai@poltekkes-tjk.ac.id 


\section{RUWA JURAI \\ JURNAL KESEHATAN LINGKUNGAN}

ISSN Online 2723-7796 ISSN Print 1978-6204

Volume 15, Nomor 3, Tahun 2021

PENANGGUNG JAWAB

Ketua Jurusan Kesehatan Lingkungan Politeknik Kesehatan Tanjungkarang

PIMPINAN REDAKSI

Prayudhy Yushananta, SKM, MKM (Politeknik Kesehatan Tanjungkarang)

\section{TIM REDAKSI}

Mei Ahyanti, SKM, M.Kes (Politeknik Kesehatan Tanjungkarang) Amrul Hasan, SKM, M.Epid (Politeknik Kesehatan Tanjungkarang)

Ahmad Fikri, ST, M.Si (Politeknik Kesehatan Tanjungkarang) Imam Santosa, SST, MT (Politeknik Kesehatan Tanjungkarang)

Hajimi, SKM, M.Kes (Politeknik Kesehatan Pontianak)

Ferry Kriswandana, SKM, M.Kes (Politeknik Kesehatan Surabaya) Teguh Budi Prijanto, SKM, M.Kes (Politeknik Kesehatan Bandung) Yeni Rosita, SKM, M.Kes (Politeknik Kesehatan Tanjungkarang)

Yinda Dwi Agustira, S.Pd, M.Pd (Universitas Lampung)

Rezza Dewinta, S.Pd, M.Pd (Politeknik Kesehatan Pontianak)

Nawan Prianto, SST, M.Kes (Politeknik Kesehatan Tanjungkarang)

S. Rendra Utama, SKM, M.Si (Politeknik Kesehatan Tanjungkarang)

\section{MITRA BEBESTARI}

Dr. Choiroel Anwar, SKM, M.Kes (Politeknik Kesehatan Semarang)

Dr. Nia Yuniarti Hasan, SST, MT (Politeknik Kesehatan Bandung)

Dr. Agus Purnomo, S.Si, MKM (Politeknik Kesehatan Tanjungkarang)

Dr. Heru Subaris, SKM, M.Kes (Politeknik Kesehatan Yogyakarta)

Dr. Agus Karmayana Rubaya, SKM, MPH (Politeknik Kesehatan Yogyakarta)

Winarko, SKM, M.Kes (Politeknik Kesehatan Surabaya)

\section{ALAMAT REDAKSI}

Jurusan Kesehatan Lingkungan Politeknik Kesehatan Tanjungkarang

J. H. Mena No.100, Hajimena, Kec. Natar, Kabupaten Lampung Selatan, Lampung 35145

Telepon: 0721703630 Email: ruwajurai@poltekkes-tjk.ac.id 


\section{DAFTAR ISI}

1 EFEKTIVITAS EKSTRAK DAUN PANDAN WANGI (Pandanus

$109-117$

amaryllifolius) SEBAGAI BIOLARVASIDA TERHADAP LARVA Culex Sp.

(Irma Novita Andini Putri, Prayudhy Yushananta)

DOI : http://dx.doi.org/10.26630/rj.v15i3.3067

2 EFEKTIVITAS KOMBINASI TIGA JENIS MIKROORGANISME LOKAL (MOL)

$118-123$ TERHADAP LAJU KEMATANGAN KOMPOS SAMPAH ORGANIK

(Salbiah, Salbiah, Kornelia A. Melsi, Sunarsieh, Sunarsieh)

DOI : http://dx.doi.org/10.26630/rj.v15i3.3069

3 PERBAIKAN KUALITAS AIR PAYAU MENGGUNAKAN MEDIA KABON AKTIF

$124-129$ DAN ZEOLIT

(Mega Sintya)

DOI : http://dx.doi.org/10.26630/rj.v15i32.3073

4 RANCANG BANGUN DAN OPERASIONAL REAKTOR BIOGAS TIPE PORTABLE UNTUK MENGOLAH LIMBAH KOTORAN TERNAK SAPI

(Rahmantio Fadil Saputra)

DOI : http://dx.doi.org/10.26630/ rj.v15i3.3070

5 GAMBARAN SANITASI DAN PERILAKU PENGHUNI RUMAH PENDERITA TUBERKULOSIS DI WILAYAH KERJA PUSKESMAS KEDATON KOTA BANDAR LAMPUNG TAHUN 2021

(Delvita Sari)

DOI : http://dx.doi.org/10.26630/rj.v15i3. 3072

EFEKTIFITAS EKSTRAK BUAH MENGKUDU (Morinda citrifolia) SEBAGAI PESTISIDA NABATI UNTUK PENGENDALIAN MENCIT (Mus musculus)

(Agnes Verawati Putri, Hajimi Hajimi, Zainal Akhmad)

DOI : http://dx.doi.org/10.26630/rj.v15i3. 3068

7 PERENCANAAN IPAL BIOFILTER ANAEROB-AEROB DI PUSKESMAS WAY HALIM KOTA BANDAR LAMPUNG

(Rahmat Fauzi Rama Dani)

DOI : http://dx.doi.org/10.26630/rj.v15i3. 3074 